\title{
TOWARDS INNOVATIVE METHODS OF CONSTRUCTION COST MANAGEMENT AND CONTROL
}

\author{
TGK Vasista \\ Ph D Research Scholar \\ SunRise University, Alwar
}

\begin{abstract}
Project cost is one of the three main challenges for the construction manager, where the success of a project is judged by meeting the criteria of cost with budget, schedule on time, and quality as specified by the owner. Many projects experience extensive delays and thereby exceed initial time and cost estimate. Available information, good estimating practice and experienced personnel are some of the factors found to have considerable impact on estimation accuracy. The successful execution of construction projects and keeping them within estimated cost and prescribed schedules depend on a methodology that requires sound engineering judgment. So the research aim is to conduct research study and process of exploring the existing model related to above three types of estimate and their contribution to civil engineering cost management and control especially getting motivated with the verification and validation component of CRASP methodology. The objective of this paper or scope of this research in this paper is to conduct literature study and review towards exploring innovative techniques such as Artificial Intelligence Techniques or Expert System Techniques available and applicable to make decision making or decision support regarding construction cost management and control at three levels: (i) before the actual civil engineering project design begins (ii) after detailed design but before execution and (iii) during project execution
\end{abstract}

\section{KEYWORDS:}

Intelligent methods, project cost estimation and control, construction cost estimation, innovative methods in construction management

\section{INTRODUCTION}

Project cost is one of the three main challenges for the construction manager, where the success of a project is judged by meeting the criteria of cost with budget, schedule on time, and quality as specified by the owner (Rezaian, 2011). Therefore, effective estimating and costing becomes important factors of a construction project success (Al-Shanti, 2003). Accordingly, cost estimate prior to the actual execution also takes place plays a significant role in any construction project (Ayed, 1997), so that owners and planners can evaluate project feasibility and control costs effectively. Indeed, cost overruns can lead to cancellation of a project (Feng et al., 2010). The decisions made at early phase affects the cost of building. Thus cost estimation is an essential part of construction projects, where cost is considered as one of the major criteria in decision making at early stages of building design process (Gunaydm \& Dogan, 2004).

DOI:10.5121/civej.2017.4102 


\subsection{Quantity Surveying and Role of Quantity Surveyor}

Quantity surveying provides an important knowledge of understanding the implications of a construction project design decision at an early stage, which can ensure obtaining good value for money to be expended. Traditional quantity surveying is concerned with contracts and costs on construction projects and the construction costs are controlled by quantity surveyors by accurately measuring the work required for the completion of civil engineering project. These methods involve a range of activities that could include value management, tendering, valuation, change control, claims management and cost estimation. The quantity surveyor facilitates the design process by systematic application of cost criteria so as to maintain a sensible and economic relationship between cost, quality, utility and appearance which thus helps in achieving the client's requirements within the agreed budget. Quantity surveyors play a good role in the area of contract administration and all aspects of the surveyor's professional work relate directly or indirectly to construction work of all kinds. The Quantity surveyor has traditional independent role in the team comprising client, architect, engineer and contractor combined with expertise in drafting and interpretation of contract document that will avoid disputes and ensure the effective progress of a project (Maarouf \& Habib, 2011).

\subsection{Causes for delays in construction projects}

Many projects experience extensive delays and thereby exceed initial time and cost estimate (Odeh \& Battaineh, 2002). Delay on construction projects are a universal phenomenon. They are almost accompanied by cost and time overruns (Desai \& Bhatt, 2013). Further, Desai \& Bhatt (2013) have categorized the causes of delay in construction project as: (i) Project related (ii) Owner related (iii) contractor related (iv) consultant related (v) design-related (vi) material related (vii) equipment related (viii) labor related (ix) external factors depending on nature and mode of occurrence. The result of a survey conducted by Odeh \& Battaineh (2002) in Joardan indicated that owner interference, inadequate contractor experience, financing and payments, labor productivity, slow decision making, improper planning and subcontractors are among the top ten most important factors that are agreed by contractors and consultant as causes for delays. The research results conducted by El-Razek, Bassioni \& Mobarak (2008) in Egypt indicated the most important causes as: financing by contractor during construction, non-utilization of professional construction/contractual management, opposing views of contractor and owner. In construction, delay could be defined as the time overrun either beyond completion date specified in a contract or beyond the date that the parties agreed upon for delivery of a project. It is a project slipping over its planned schedule and is considered as common problem in construction project. In owner terms, delay means loss of revenue through lack of production facilities and rentable space or a dependence on present facilities. For a contractor it could overhead cost as a result of longer work period, higher material cost through inflation and labor cost (Desai \& Bhatt, 2013). Delay was also defined as an "act or even which extends required time to perform complete work of the contract manifests itself as additional days of works (Zack, 2003). Assaf et al. (1995) in Saudi Arabia mentioned approval of drawing, delays in payments to contractors and the resulting cash problems during construction, design changes, conflicts in work schedules of subcontractors, slow decision making and executive bureaucracy in the owners' organizations, design errors, labor shortage and inadequate labor skills. Important causes for delay in Indian Industry as mentioned by Venkatesh, Renuka \& Umarani (2012) include: shortage of labors, delivery of materials, shortage in construction materials, extra works and reworks, preparation of scheduling networks and revisions, skill of labors, procurement of materials, material section and changes in 
types and specifications, maintenance of equipment and adverse weather effect on construction activities.

\subsection{Accuracy of Estimation}

The word accuracy is defined in Webster's dictionary (1999) as "the condition or quality of being true, correct or exact, precision; exactness; the extent to which a given measurement agrees with the standard value for that measurement". From the structural perspective the accuracy is defined as "the degree to which a measurement or calculation varies to its actual value (Dysert, 2006). In general, the accuracy of any estimate depends on the amount of information available at the time of the estimate. The range of accuracy increases as the quantity and quality of information increases through the life of project. The range of accuracy increases as the quantity and quality of information increase through the life of a project. Therefore available information, good estimating practice and experienced personnel are some of the factors found to have considerable impact on estimation accuracy. The CII (1998) study highlighted the major factors that are influencing the accuracy of estimate as: (i) quality and amount of information available for preparing the estimate (ii) Time allocated to prepare the estimate (iii) Proficiency of the estimator and the estimating team and (iv) tools and techniques used in preparing the estimate. The relationship between the accuracy of estimate and time phases of the project can be expressed as shown in figure 1, where the positive error curve is not similar to negative error curve because the opportunity of increasing the project budget is more than expected and is greater than decreasing. In general the probability of increasing the prices as materials, a labor etc. of a project is more than decreasing.

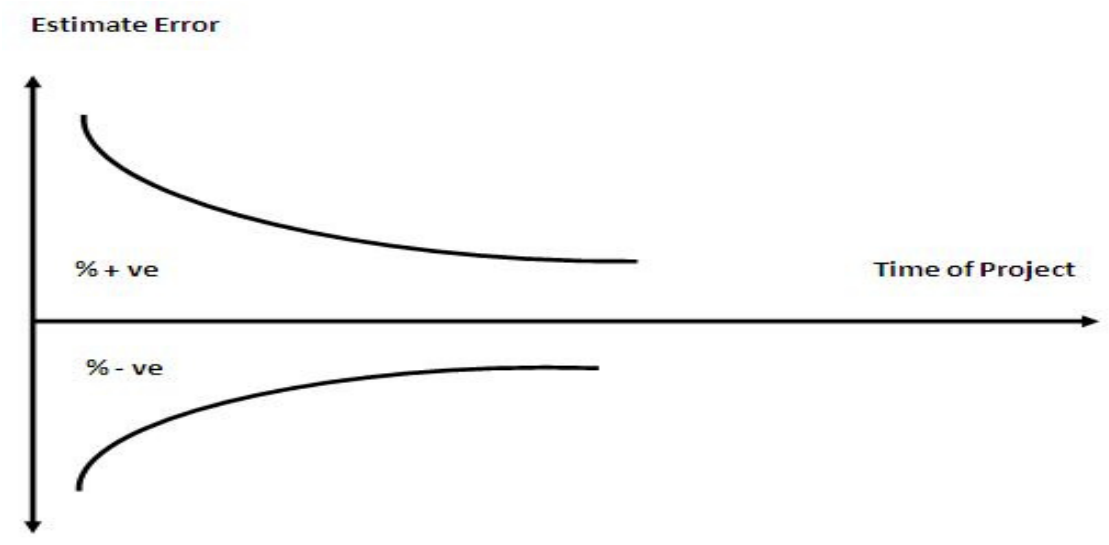

Fig.1 Relationship between time and estimate accuracy (Dysert, 2006)

\section{BASE METHODOLOGY}

The successful execution of construction projects and keeping them within estimated cost and prescribed schedules depend on a methodology that requires sound engineering judgment (Hancher \& Rowings, 1981). Vasista (2016) [in passing] suggested CRASP model as a management methodology model to determine the project management success. Further his proposition also suggested and concluded that it is important to consider automation and intelligent techniques in the construction industry and construction works where it is difficult to involve human labor intervention especially at very large and complex construction project. 


\section{TYPES OF ESTIMATES}

CRASP methodology encourages and supports three kinds of decision-making capabilities viz. (i) Subjective (ii) Objective and (iii) Hybrid. The factors that are considered to be provided as rational for having this classification are(i) estimator specific,(ii) design specific and (iii) project specific (Elfaki, Alatawi \& Abushandi, 2014).

From the Perspective of understanding the CRASP methodology and kind of decision-making capability, three types of estimates can be proposed, which can be broadly categorized into: (i) Conceptual Estimate and (ii) Detailed Estimate (iii) Hybrid estimate and are briefly discussed below:

\subsection{Conceptual Estimate}

The purpose of conceptual estimate is to determine the approximate cost of a project before making a final decision to construct it. It is also otherwise called an approximate estimate and the understanding is subjective in nature. Clear understanding of what an owner wants and a good feel of the probable costs become requirements. As there are no details of designs and drawings that can be available, it is said to be having limited information availability on project scope. Therefore this kind of estimate is adoptable at the beginning of the project while at studying/determining the feasibility study. However, it works better only for the accuracy range of -30 percent to +50 percent.

\subsection{Detailed Estimate}

The purpose of a detailed estimate is to determine the reliable cost of a project and make a contract. In this kind of estimate, it is required to conduct an analysis of the method of construction to be used, quantities of work, production rate and factors that affect each sub-item. As the scope of work is clearly defined and the detailed design is identified, it is possible to takeoff their quantities through accessing detailed specifications mentioned in drawings and the information from subcontractors. The accuracy range of this kind of estimate is possible through the range from -5 percent to +15 percent.

\subsection{Hybrid Estimate}

The purpose of Hybrid estimate is to determine the reliable cost as well as to make best possible decision on determining the feasibility, conduct and execution of construction project at optimized level. Therefore it is required to adopt both the knowledge based and object based details of data and information considerations of conceptual estimate and detailed estimate. The accuracy range of this kind of probabilistic estimate but based on realistic cost details and information obtained from historical patterns of similar kind of projects is proposed and expected through the range of -1 percent to +5 percent to support effective decision making on managing and controlling the construction cost.

\section{RESEARCH OBJECTIVE AND SCOPE}

So the research aim is to conduct research study and process of exploring the existing model related to above three types of estimate and their contribution to civil engineering cost management and control especially getting motivated with the verification and validation component of CRASP methodology. Therefore this paper is organized as 1. Introduction 2. 
Methodology 3. Types of Estimates 4. Research Aim and Objective of this paper or research scope of this paper and 5. Literature Study and Review.

The objective of this paper or scope of this research in this paper is to conduct literature study and review towards exploring innovative techniques such as Artificial Intelligence Techniques or Expert System Techniques available and applicable to make decision making or decision support regarding construction cost management and control at three levels: (i) before the actual civil engineering project design begins (ii) after detailed design but before execution and (iii) during project execution

Thus this paper investigates and summarizes the current use of intelligent solutions proposed or used in the construction industry. In order to leverage the importance of intelligent solutions in project cost estimation a list of state-of-the-art methods are required to be analyzed including machine-learning, rule-based systems, evolutionary systems, agent-based systems and hybrid systems

\section{RESEARCH METHODOLOGY}

The importance of cost estimation in the construction industry has been discussed in previous sections of this paper.

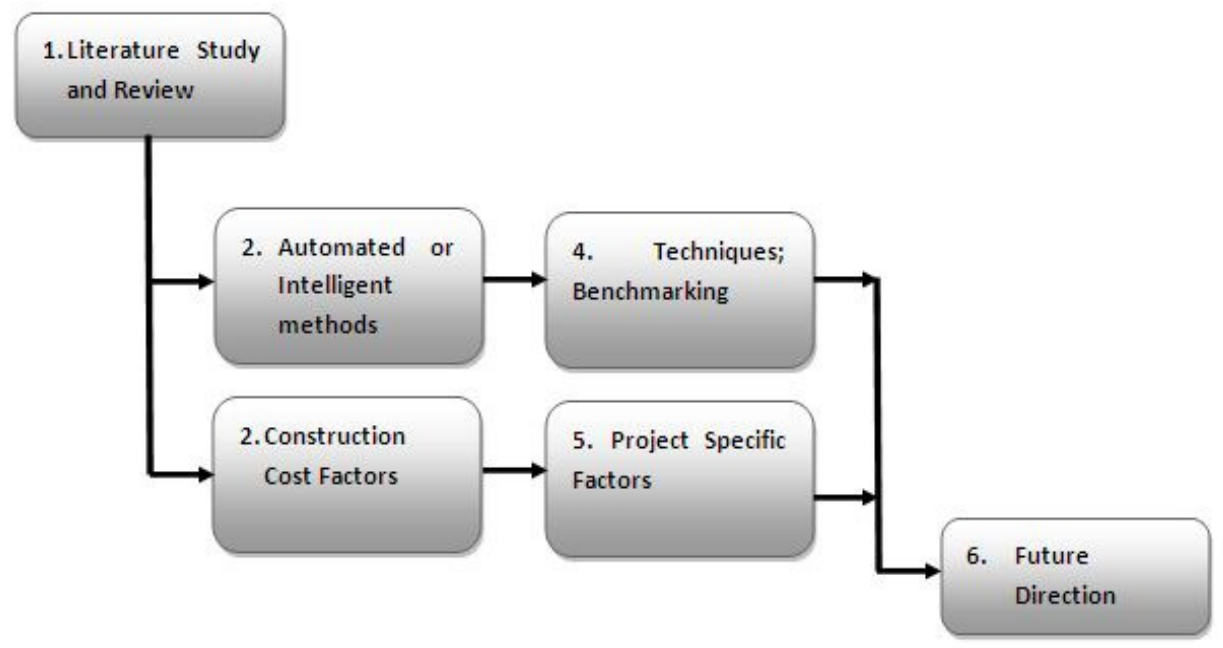

Fig. 2 Flow illustrating the research methodology

However, there is no doubt that automated and intelligent solutions may solve the dilemma of cost overruns, considering all affecting factors. In fact there is huge number of intelligent techniques available to deal with problems in construction management. In order to meet the research paper objective, a flowchart illustrating the research methodology has been developed.

\section{LITERATURE STUDY AND REVIEW}

A building project is normally a financial enterprise. In general, a developer of such a project aims at minimizing the costs and maximizing the benefits of the project (Haber \& Karshenas, Undated). 


\subsection{Innovative methods related to Conceptual Estimation}

Conceptual estimating is strategically important because it is an essential part of project planning (Kim, Seo \& Hyun, 2012.) Conceptual refers to a stage in a project or task when the final product is not fully defined. The cost estimating involves predicting expected costs for a future project or task. Thus conceptual cost estimating is the task of predicting expected costs for a future project when the form of the final-product is not completely defined. Conceptual estimates are made in the early phases of a project to tell an owner whether a contemplated project scope is anywhere near to being economically feasible. Since the engineering design of a project is not complete at the conceptual stage, detailed estimates based on computed quantities are impossible. The owner can only provide the estimator with the general concept, site information and location (Tauber, Levitt, Oralkan, Reinberg \& Walsh, 1992).

The research conducted by Harber \& Karshenas (Undated) has good elucidation on how and what to consider when focusing on innovative method based solutions to conceptual cost estimation, and understanding its management and control for a building construction project. So the following has been extracted from their research efforts.

"In the conceptual design stage of a building, the number of possible configurations is enormous. Configurations selected in this stage do affect the building cost much more than any decision made in subsequent design stages. Currently there is no analytic method for selecting the best solution, and designers base their decisions mostly on experience and intuition. This process is not algorithmic and therefore the best possible design is not guaranteed. In that respective, a building design, the conceptual and the detailed designs, can be viewed as the process of selecting the optimal configuration that maximizes the developer's return within given constraints. However the relation between the building components and the design objective are difficult to formulate. But it is quite easy to calculate the costs of different building components; many construction databases hold this information. It is difficult to clearly obtain the beneficial value from the estimate such as privacy, circulation, view, acoustics and appearance ....all of these could affect the market value of a building. The conceptual design's ultimate goal is to optimize an objective function and thus the design process is best described through an optimization process. For example, the factors related to conceptual design related algorithm could refer to several types of knowledge such as: hard constraints, heuristics, owners' preference, cost of building categories and costs and load of building components" (Harber \& Karshenas, Undated). The research conducted by Rao et al. (Undated) presented a hybrid neutral-expert system approach for developing conceptual cost estimates based on historical data of construction projects. This expert system considers a large number of project parameters, it can self-organize, learn from new information and can function with despite the incomplete data input and explain the logic behind its conclusions (Rao, Grobler \& Kim, Undated). Tauber, Levitt, Oralkan, Reinbert \& Walsh (1992) at Stanford University developed an expert system called the Conceptimator for estimating the cost of a building foundation by simulating the design process. It is designed not for civil engineers or building construction experts but for non-technical users. The conceptimator has the ability to put knowledge of many experts in the building construction field into the hands of the future building owner by producing a detailed conceptual estimate at a stage of the project when some of the data needed to estimate unambiguously are missing. The system gives the following output: a product model for the designed building with selected 
foundation; an AutoCAD drawing of the foundation, report that summarizes the input to the system; the allowable foundation types and cost for each one, and a detailed description of geometry and cost of the chosen foundation. The system is developed as a prototype (i.e. proofof-concept) in order to show that conceptual estimating can be done by design rather than classification. The conceptimator uses model based reasoning for synthesis rather than associative reasoning.

An expert system for taxonomy based calculation of manufacturing costs that is determined by considering cost entities using pertinent inductors and parametric calculation methods is developed and proposed by Martin, Dantan \& Siadat (2007).

\subsection{Innovative methods related to Detailed Estimate}

The use of Building Information Modeling (BIM) in the construction industry is on the rise. Cost estimation is a key aspect in the workflow of a construction project. The Process within estimating such as quantity survey and pricing may be automated by using existing BIM software in combination with existing estimating software. BIM follows a model based cost estimating methodology where the process of integrating the object attributes from the 3D model of the designer with the cost information from the database of the estimator. The BIM kind of estimating methods facilitate the increased control of time and costs in a construction project. A survey results on the use of BIM for estimating sake revealed that BIM has improved the quality of estimating (about 48 percent responses) and about 69 percent selected that BIM has improved the quality of estimating (Sattineni \& Bradford II, 2011 ).

The first step of cost estimate is quantification- and the computable information at the heart of building information model makes quantification effortless. Though Building Information models do not generate automatic cost estimates by any means, yet they offer significant advantages over traditional drawing based systems by minimizing manual takeoffs. More accurate quantities of materials results in more accurate cost estimates. It allows architects can use the information within their design model to easily double check estimating quantities - facilitating concurrent estimating during the design process. Applications such as Revit Architecture, Revit Structure and Revit MEP built on the Revit platform are complete, discipline specific building design and documentation. Revit is a purpose-built solution for building information modeling. BIM enable computable building information that supports numerous building design and construction activities such as structural analysis, system modeling, building energy analysis and specification management etc. Cost estimation is also possible with BIM. When preparing cost estimates, estimators typically begin by digitizing the paper drawings and import them into cost estimating package. By using BIM (instead of drawings, the takeoffs, counts and measurements can be generated directly from the underlying model. Therefore the information is always consistent with the design and any change happens could automatically ripples to all its related construction documentation and schedules and measurements that are used by the estimators. The following are some of the advantages of BIM: (i) BIM models help in quantification that leads to faster, more accurate cost estimates and updates. (ii) BIM in association with Revit enables the innovative estimating solutions to count and calculate materials directly from the Revit BIM. (iii) It is possible to generate customizable cost estimates. It is also possible to get accurate quantities for cost estimates; extracting quantities from the Revit building information model, outputting them to a text file, importing that to Excel and then sending the spreadsheet to their estimators for 
costing. It is possible to produce two cost estimates: and (ii) complete estimate at the end of detailed design. (Autodesk, 2007).

\subsection{Innovative methods related to Hybrid Estimation}

A hybrid model is the one in which quantity-based and historical data-based estimating methods are combined. Each method has its own limitations. In the conceptual phase, quantities and unit costs are uncertain: the design and specification are incomplete, thus a quantity-based estimate may have a low accuracy. If there are no highly similar historical projects, historical projects, a historical-based estimate could lead to over- or underestimations. However, when combined and compared, the estimates can reduce their weakness and fulfill the estimators' whishes. This kind of hybrid estimate refers to contain five critical elements such as: (i) project information (ii) historical data (iii) current data (iv) estimating methodology and (v) cost estimator (Kim, Seo\& Hyun, 2012).

Rahaman et al. (2008) research study aims to develop a knowledge based cost modeling system for building design stage by optimizing the selection of materials and technology. It was adopted to design database and knowledge base modules in order to achieve the knowledge-based cost modeling system. The knowledge base also incorporates the multi criteria decision making, which helps in solving the combinational problem. It was targeted to be developed to assist the architects, design teams, quantity surveyors and self house buildings to make a decision for the design from early stage to detailed design stage by selecting appropriate materials and technology and estimating cost. The life cycle cost or whole life cost of building is the sum of all costs incurred during the life of it. Life Cycle Cost may be used as an instrument for optimizing buildings and for the exploitation of the economic principles of sustainability (Pezeter, 2007). This research refers to Topsis method of ranking for determining the performance criteria requirements of civil engineering project construction. Using the score, it evaluates to rank the materials for cost estimation. The materials and corresponding performance can be retrieved from the database. Using the unit cost of the selected material that is retrieved from the design element database, the total cost of the project is computed.

\section{CONCLUSION}

The higher the levels of innovation in the construction industry, the greater the likelihood of increasing its contribution to economic growth can be observed. Therefore for the developing countries like India there is much room for improvement. Government reports commissioned in recent years have identified such problems as poor rates of investment research and development ( $R \& D$ ), fragmented supply chain and lack of coordination between academia and industry in research activities. These are not only issues to public policy makers but also to industry participants where there is a need to review the capacity of innovation in the engineering and construction firms. Development and effective use of new technology can provide important competitive advantages for engineering and construction forms. These competitive advantages stem from distinctive technical capability, improvement in operations and image as a technically progressing company (Blayse \& Manley, 20014)

The refinement of the schedule relies on the accuracy of the construction manager to review the new design document each time and judge the project availability for additional equipment, 
Civil Engineering and Urban Planning: An International Journal (CiVEJ ) Vol.4, No.1, March 2017

material quantities and so on. The schedule, and the subsequent revisions, is one of the more time-intensive aspects of a project, and the members of the team rely on its accuracy to deliver a project to the owner on time (Hardin \& McCool, 2015).

\section{Future Research}

Within the last two decades, substantial amount of literature on intelligent building has been generated. However, there is a lack of systematic review of existing research efforts and achievements. A comprehensive on existing research provides great benefits to identify where more efforts are needed and therefore can provide directions to future research needs. This review indicates that previous research efforts have dealt mainly with research aspects including advanced and innovative intelligent technologies research, performance evaluation methodologies and investment evaluation analysis. Relatively less literature can be found in the area of investment of evaluation of use of intelligent methods in construction industry.

It is also further planned to develop a model to estimate the cost of building construction projects with a better degree of accuracy and without the need for detailed information or drawings by using intelligent methods such as Artificial Neural Network (ANN).

\section{REFERENCES}

1. Al-Shanti, Y. (2003). A Cost Estimate System for Gaza Strip Construction Contractors, Palastine, Master thesis in construction management, The Islamic University of Gaza strip.

2. Assaf, S. A., Al-Khalil, M. \& Al_Hami, M. (1995). Causes of delay in large building construction projects. Journal of Management in Engineering, ASCE, 11(2), 45-50.

3. Autodesk. (2007). BIM and Cost estimating. [Online]URL: http://images.autodesk.com/apac_grtrchina_main/files/aec_customer_story_en_v9.pdf

4. Ayed, A. S. (1997). Parametric Cost Estimating of Highway Projects using Neural Networks, Canada: National Library of Canada.

5. Blayse, A. M. \& Manley, K. (2004). Key influences on construction innovation, Construction Innovation, 4(3), 143-154.

6. Desai, M. \& Bhatt, R. (2013). Critical Causes of Delay in Residential Construction Projects: Case study of Central Gujarat Region of India. International Journal of Engineering Trends and Technology (IJETT) - 4(4), 762.

7. Dysert, L. R. (2006). Is "estimate accuracy" an oxymoron?, AACE International Transactions. EST01.1-01.5. [Online] URL: http://www.costengineering.eu/images/papers/Is_Estimate_Accuracy_an_Oxymoron.pdf Accessed on Jan 10, 2015

8. Elfaki, A.O., Alatawi, S. \& Abushandi, E.(2014). Using Intelligent Techniques in Construction Project Cost Estimation: 10-Year Survey. Advances in Civil Engineering, Article ID 107926,11 Pages.fala

9. El-Razek, M. E. A., Bassioni, H. A. \& Mobarak, A. M. (2008). Causes of Delay in Building Construction Projects in Egypt. Journal of Construction Engineering and Management, ASCE, 831-841.

10. Feng, W., Zhu, W. \& Zhoud, Y.(2010). The Application of Genetic Algorithm and Neural Network in Construction Cost Estimate, Guangzhou, P. R. China, 29-31, July, 151-155

11. Harber, D. \& Karshenas, S. (Undated). An Expert System for Conceptual Design of Buildings. [Online]

URL: http://www.iaarc.org/publications/fulltext/An_expert_systems_for_conceptual_design_of_buildin gs.PDF Accessed on Jan 10, 2016. 
Civil Engineering and Urban Planning: An International Journal (CiVEJ ) Vol.4, No.1, March 2017

12. Hancher DE \& Rowings IE (1981). Setting highway construction contract duration. Journal of Construction Engineering and Management, ASCE, 107(2), 169-178

13. Hardin, B. \& McCool, D. (2015). BIM and Construction Management: Proven Tools, Methods and Workflows. Canada: Sybex

14. Kim, H-Y, Seo, Y-C \& Hyun, C-T (2012). A hybrid conceptual cost estimating model for large building projects. Automation in Construction, 25, 72-81.

15. Maarouf, R. \& Habib, R. (2011). Quantity surveying role in construction projects - a comparison of roles in Sweden and the UK Thesis submitted to Malmo University

16. Martin, Dantan \& Siadat (2007). Cost Estimation and Conceptual Process Planning. Chapter in Digital Enterprise Technology: Perspectives and Future Challenges, 243-250, Springer

17. Odeh, A. M. \& Battaineh, H. T.(2002). Causes of construction delay: traditional contracts. International Journal of Project Management, 20, 67-73.

18. Rao, G. N. Grobler,F. \& Simon, K. (Undated). Conceptual Cost Estimating: A Hybrid NeutralExpert System Approach. [Online] URL: http://cedb.asce.org/cgi/WWWdisplay.cgi?9302389 Accessed on Jan 10, 2016.

19. Rahman, S., Perera, S., Odeyinka, H and Bi, Y. (2008). A conceptual knowledge-based cost model for optimizing the selection of materials and technology for building design. In: Dainty, A. (Ed) Procs of $24^{\text {th }}$ Annual ARCOM Conference, 1-3 September, Cardiff, UK, Association of Researchers in Construction Management, 217-225.

20. Rezaian, A. (2011). Time-Cost-Quality-Risk of Construction and Development Projects or Investment. Middle-East Journal of Scientific Research, 10(2), 218-223.

21. Sattineni, A. \& Bradford II, R. H. (2011). Estimating with BIM: A survey of US Construction Companies. Proceedings of the $28^{\text {th }}$ ISARC, Seoul, Korea, 564-569

22. Tauber, E. R., Levitt, R.E., Oralkan, G.A.Reinberg, F. C.\& Walsh, T. J. (1992). The Conceptimator: An Expert System for Conceptual Cost Estimating of Building Foundations. CIFE Working Paper No, 14. [Online] URL: http://cife.stanford.edu/sites/default/files/WP014.pdf Accessed on January 10, 2016.

23. Vasista, T. G. K. (2016). Determining Project Management Success Model: Viewing Through the Application of CRASP Methodology Approach. In National Conference on Operations Research and Management - A strategy towards competitive advantage (NCORM-2016), Chaitanya Bharathi Institute of Technology, Hyderabad, Telangana.

24. Venkatesh, M. P., Renuka, S. M., Umarani, C. (2012). Causes of delay in Indian construction industry. Applied Mechanics and Materials. 174(177), 2768-2773. Transtech publication, Switzerland. 